\title{
Genetic variation in intramuscular fat of prime lambs supplemented with varying concentrations of degummed crude canola oil
}

\author{
Aaron Ross Flakemore ${ }^{1}$, Razaq Oladimeji Balogun ${ }^{2}$, Peter Daniel McEvoy ${ }^{1}$, \\ Bunmi Sherifat Malau-Aduli ${ }^{3}$, Peter Nichols ${ }^{4}$, Aduli Enoch Othniel Malau-Aduli ${ }^{1,5}$, * \\ ${ }^{1}$ Animal Science and Genetics, Tasmanian Institute of Agriculture, School of Land and Food, Faculty of Science, Engineering and \\ Technology, University of Tasmania, Sandy Bay, Hobart, Australia \\ ${ }^{2}$ Coprice Feeds, PO Box 104 Cobden, Victoria 3266, Australia \\ ${ }^{3}$ School of Medicine and Dentistry, Faculty of Medicine, Health and Molecular Sciences, James Cook University, Townsville, Australia \\ ${ }^{4}$ Commonwealth Scientific and Industrial Research Organisation Food Futures Flagship, Division of Marine and Atmospheric Research, \\ Hobart, Australia \\ ${ }^{5}$ School of Veterinary and Biomedical Sciences, Faculty of Medicine, Health and Molecular Sciences, James Cook University, \\ Townsville, Australia
}

\section{Email address:}

Aduli.MalauAduli@utas.edu.au (A. E. O. Malau-Aduli), aduli.malauaduli@jcu.edu.au (A. E. O. Malau-Aduli)

\section{To cite this article:}

Aaron Ross Flakemore, Razaq Oladimeji Balogun, Peter Daniel McEvoy, Bunmi Sherifat Malau-Aduli, Peter Nichols, Aduli Enoch Othniel Malau-Aduli. Genetic Variation in Intramuscular Fat of Prime Lambs Supplemented with Varying Concentrations of Degummed Crude Canola Oil. International Journal of Nutrition and Food Sciences. Vol. 3, No. 3, 2014, pp. 203-209.

doi: $10.11648 /$ j.ijnfs.20140303.22

\begin{abstract}
The main objective of this study was to quantify the intramuscular fat (IMF) content of Longissimus thoracis et lumborum, biceps femoris and triceps brachii muscles in genetically divergent lambs supplemented with varying levels of degummed crude canola oil (DCCO). Over a nine-week feeding trial, twenty-four first-cross prime lamb progeny from Merino, Dorset and White Suffolk rams mated with purebred Merino ewes under the same nutritional management were supplemented with one of three levels of wheat-based pellets with or without DCCO. The experimental treatments included the Control (1 kg of plain wheat-based pellets without DCCO/head/day on dry matter basis), High ( $1 \mathrm{~kg}$ of wheat-based pellets containing $50 \mathrm{ml}$ of $\mathrm{DCCO} / \mathrm{kg} / \mathrm{head} /$ day on dry matter basis) and Medium $(500 \mathrm{~g}$ of Control $+500 \mathrm{~g}$ of High wheat-based pellets/head/day on dry matter basis). All lambs had a three-week adjustment period and had ad libitum access to lucerne hay and water. After nine weeks of supplementation, all experimental lambs were slaughtered at a commercial abattoir with the exception of four purebred Merino ewes retained in the flock for breeding purposes. IMF content was analysed using a 2:1 vol/vol ratio of chloroform/methanol extraction and precipitated with $10 \%$ potassium chloride. IMF content varied significantly with the level of DCCO supplementation $(\mathrm{p}<0.0125)$ and muscle type $(\mathrm{p}<0.0001)$. There were also highly significant interactions between sire breed and level of DCCO supplementation $(\mathrm{P}<0.0016)$, and muscle type and $\operatorname{sex}(\mathrm{P}<0.0003)$ in IMF content. Prime lambs in the Control and Medium level of DCCO supplementation had the most IMF (3.18 \pm 0.12 and $3.28 \pm 0.14 \%$, respectively) and the High treatment had the least $(2.96 \pm 0.10 \%)$, suggesting a decrease in IMF as supplementation levels with DCCO increased. The Longissimus thoracis et lumborum had more IMF $(3.69 \pm 0.11 \%)$ than the biceps femoris $(2.87 \pm 0.11 \%)$ ) and triceps brachii $(2.90 \pm 0.12 \%)$ muscles. It was also evident that in ewes, the biceps femoris had the least IMF (2.4\%) compared with Longissimus thoracis et lumborum (3.6\%). This result indicates that supplementation of prime lambs with DCCO can be used as a management tool to vary the level of IMF content to suit different market specifications dictated by meat consumers. Whereas in themselves, sex and sire breed of lambs used in this study were not the primary drivers of IMF deposition, our results demonstrate that sheep farmers can modify their nutritional management and breed combinations by effectively utilizing appropriate sire breed and supplementation level combinations to manipulate the IMF content of various muscle types in ewe and wether prime lambs.
\end{abstract}

Keywords: Degummed Crude Canola Oil, Intramuscular Fat, Longissimus Thoracis et Lumborum, Biceps Femoris, Triceps Brachii 


\section{Introduction}

Animal fat, when consumed in high concentrations, can be detrimental to human health, because it can trigger the on-set of diabetes, cardiovascular disease and inflammatory disorders $[1,2,3]$. As a consequence, medical recommendations have encouraged reduced dietary fat intake, particularly from red meat sources $[1,4$. This has sequentially led to consumers preferring leaner, healthier red meat cuts containing minimal fat quantities [5]. However, from an eating quality perspective, it has been demonstrated that intramuscular fat (IMF), also referred to as marbling, significantly influences meat eating quality attributes of tenderness, juiciness and flavour $[6,7,8]$. In order to achieve acceptable consumer satisfaction in uncooked lamb meat, a minimum ether extractable IMF content ranging from $3-4 \%$ and $5 \%$ has been suggested [9, 10]. Therefore, one of the major challenges facing the red meat industry is to produce healthier and leaner cuts while maintaining IMF levels that are acceptable for eating quality.

In some markets, notably in beef destined for the Japanese, Korean and USA markets, IMF content in meat is a highly sought-after characteristic [4, 11]. However, unlike fats from other depots, IMF cannot be readily trimmed during processing or preparation for consumption. IMF has the greatest influence on marketability of meat compared to other fat depots. In order to achieve market specifications for IMF and earn high price premiums, it is important for researchers to test all possible variations and geneticsnutrition interactions that prime lamb producers can best utilise to manipulate IMF content of meat. Some studies have reported identifiable differences in IMF content between muscle types [12, 13, 14], genetically divergent sire breeds [15, 16] and sexes [17]. The nutritional manipulation of IMF has also been demonstrated in other studies $[18,19,20,8]$.

Some researchers $[21,22]$ have identified glucose as the preferred precursor in the metabolic pathway for IMF deposition in beef cattle. However, research investigations into the impact of dietary oil supplementation on IMF deposition in ruminants have been inconsistent in outcomes [22]. Nevertheless, there is increasing research interest in dietary oils as sources of energy-dense supplements in ruminant rations and impact on consumer preferences for healthier leaner meats [23], hence further research investigations into oils in sheep diets and their subsequent effects on IMF deposition are warranted.

Research evaluating the effects of degummed crude canola oil as a supplementary feed source in animal diets has been relatively scanty, if not completely neglected. Therefore, there is need to evaluate its potential use as a dietary supplement in sheep diets and to investigate if there are genetic variations between prime lambs in IMF deposition in response to dietary oils. In this study, we investigated the impact of supplementing prime lambs with degummed crude canola oil (DCCO) on IMF levels in prime lambs sired by genetically divergent rams under the same on-farm management conditions. Additionally, we examined differences in IMF deposition between muscle type and sex of lambs. Our primary hypothesis was that incremental levels of degummed crude canola oil supplementation will increase IMF levels in the muscle types of genetically divergent ewe and wether prime lambs. Therefore, the objective of this study was to compare the IMF contents of Longissimus thoracis et lumborum (LTL), biceps femoris (BIF) and triceps brachii (TRI) muscles in ewe and wether lambs sired by genetically divergent rams supplemented with varying concentrations of DCCO.

\section{Materials and Methods}

\subsection{Animal Welfare and Ethics Approval}

This study and all experimental protocols were approved by the University of Tasmania Animal Ethics Committee in accordance with the 1993 Tasmanian Animal Welfare Act and the 2004 Australian Code of Practice for the Care and Use of Animals for Scientific Purposes. The feeding trials were conducted from the 21st February to the 24th April 2013 at the University of Tasmania Farm, Cambridge, Hobart, Australia.

\subsection{Animals and Management}

Twenty-four, six-month old, first-cross, weaner prime lambs were subjected to a nine-week feeding trial using an experimental design that included three sire breeds, three levels of degummed crude canola oil supplementation and two sexes. The prime lambs were progeny from mating Merino, Dorset and White Suffolk rams with Merino ewes. Each genotype had eight lambs balanced by gender comprising four ewes and four wethers. Following an initial three-week adjustment period, lambs were supplemented daily with one of three levels of degummed crude canola oil over a six-week period. The experimental treatments included the Control (1 kg of plain wheat-based pellets without DCCO/head/day on dry matter basis), High (1 $\mathrm{kg}$ of wheat-based pellets containing $50 \mathrm{ml}$ of $\mathrm{DCCO} / \mathrm{kg} / \mathrm{head} /$ day on dry matter basis) and Medium $(500 \mathrm{~g}$ of Control $+500 \mathrm{~g}$ of High wheat-based pellets/head/day on dry matter basis). All lambs were housed in individual metabolic crates in a well-ventilated shed and had ad libitum access to lucerne hay and water throughout the feeding trial. Table 1 shows the nutritional composition of the experimental feeds.

Table 1. Composition of experimental diets (\%).

\begin{tabular}{cccc}
\hline Component & $\begin{array}{c}\text { DCCO enriched } \\
\text { pellets at } \\
\text { 50ml/kg (High) }\end{array}$ & $\begin{array}{c}\text { Plain wheat-based } \\
\text { pellets without } \\
\text { DCCO (Control) }\end{array}$ & $\begin{array}{c}\text { Lucerne } \\
\text { hay }\end{array}$ \\
\hline DM & 91.8 & 90.9 & 85.6 \\
CP & 12.7 & 10.4 & 17.0 \\
ADF & 8.0 & 9.0 & 44.9 \\
\hline
\end{tabular}




\begin{tabular}{cccc}
\hline Component & $\begin{array}{c}\text { DCCO enriched } \\
\text { pellets at } \\
\text { 50ml/kg (High) }\end{array}$ & $\begin{array}{c}\text { Plain wheat-based } \\
\text { pellets without } \\
\text { DCCO (Control) }\end{array}$ & $\begin{array}{c}\text { Lucerne } \\
\text { hay }\end{array}$ \\
\hline NDF & 20.0 & 21.1 & 55.2 \\
TDN & 75.7 & 72.0 & 55.4 \\
Ash & 9.7 & 8.9 & 6.8 \\
CF & 6.2 & 2.1 & 7.5 \\
\hline
\end{tabular}

All components were measured on a dry matter basis. Dry Matter (DM); Crude Protein (CP); Acid Detergent Fibre (ADF); Neutral Detergent Fibre (NDF); Total Digestible Nutrient (TDN); Crude Fat ; Degummed Crude Canola Oil (DCCO)

\subsection{Sample Preparation and Collection}

Animals were prepared for slaughter in the morning of the final day of the feeding trial. Four Merino ewes were retained in the flock for breeding purposes, while the remaining 20 animals were loaded on a trailer and transported to a commercial abattoir in Gretna, Tasmania. Animals remained in lairage overnight where they were rested, fed and watered for approximately 16 hours at the abattoir until the following morning when they were stunned and humanely sacrificed. After slaughter and dressing, the hot carcasses were chilled for one week to enable proper aging as per Australian Meat Standards. Samples of Longissimus thoracis et lumborum (LTL), biceps femoris (BIF) and triceps brachii (TRI) muscle samples were taken from commercially prepared loin chops, leg steaks and arm chop portions, respectively. The meat cuts from each animal were placed into properly labelled individual zip-locked freezer bags, transported to the University of Tasmania, Sandy Bay Campus Hobart and stored at $-20^{\circ} \mathrm{C}$ until required for laboratory analysis.

\subsection{Determination of Intramuscular Fat}

Intramuscular fat content was analysed based on the lipid extraction procedure [24]. The frozen muscle samples were removed from $-20^{\circ} \mathrm{C}$ storage and thawed at $4{ }^{\circ} \mathrm{C}$ for approximately 16 hours in a fridge. The samples were homogenised and triplicates of $1 \mathrm{~g}$ each, placed into $50 \mathrm{~mL}$ polypropylene centrifuge tubes and $10 \mathrm{~mL}$ of chloroform/methanol $(2: 1 \mathrm{vol} / \mathrm{vol})$ solvent added before further homogenisation using an IKA T25 homogenising unit for 20 seconds at $19,000 \mathrm{rpm}$. An additional $10 \mathrm{~mL}$ of the chloroform/methanol solvent was added to the homogenate and agitated for 15 minutes at $57 \mathrm{rpm}$ using a Ratek RM4 rotary mixer. $5 \mathrm{~mL}$ of $10 \%$ potassium chloride solution was added and the homogenate centrifuged at $3000 \mathrm{rpm}$ for 5 minutes at $20^{\circ} \mathrm{C}$ using a Sorvall ${ }^{\circledR}$ Super T2 1 centrifuge. The upper layer was pipetted out and discarded and the lower layer of the homogenate was filtered using a Whatman $^{\circledR} 597$ filter paper into an empty $50 \mathrm{~mL}$ polypropylene centrifuge tube. The filtrate was transferred into a pre-weighed porcelain crucible which was then heated on a Thermo Scientific hotplate set to $100^{\circ} \mathrm{C}$ in a fume hood until the solvent had completely evaporated. The crucible was transferred to a desiccator and left for 20 minutes to cool before re-weighing. The percentage of intramuscular fat was calculated as: Final crucible weight (g) - Initial crucible weight (g)/initial sample weight (g) x 100. A total of 180 muscle samples were thus subjected to IMF extraction.

\subsection{Statistical Analysis}

The means procedure (PROC MEANS) in SAS [25] was used to generate summary statistics that included means, standard errors, minimum and maximum values and these were cross-checked for any likely data entry errors. Intramuscular fat percentage was then fitted as the dependent variable, while muscle type, supplementation level, sire breed, sex and their second-order interactions were fitted as fixed effects in a repeated measures analysis of variance using the general linear model procedure (PROC GLM) in SAS [25]. Tukey's pairwise mean comparison test at a minimum threshold of $p<0.05$ level of significance was used for means separation.

\section{Results and Discussion}

\subsection{Effect of DCCO Supplementation}

The results in Figure 1a portray significant differences in IMF content between the Medium (3.28 $\pm 0.14 \%$ ) and High $(2.96 \pm 0.10 \%)$ DCCO supplementation levels. This result was contrary to our tested hypothesis that IMF levels would correspondingly increase in response to increased levels of DCCO supplementation. The reverse seemed to be the case where IMF content decreased as the level of supplementation increased from Medium to High. However, our findings agreed with those of [26], [27] and [28] who also identified insignificant IMF deposition effects when examining the incorporation of soybean, safflower, and soybean/linseed oils in sheep diets respectively. However, other research assessing the impact of dietary oil supplementation in sheep [29, 30] observed significant increases in IMF content when supplemented fish and coconut oils, respectively, were utilised. Given the differences in experimental design between studies, it can be surmised that IMF deposition may depend upon the amount and type of oil supplemented, duration of supplementation, animal age and management conditions.

While beyond the scope of this study, the results presented herein, would suggest that the glucose induced IMF deposition pathway observed in beef cattle [21] is perhaps more complex in dual-purpose sheep due to differential partitioning of nutrients towards wool and meat. This is supported by [31] who identified that glucose production is reduced in Merino sheep when selected for increased clean fleece weight due to additional demands for amino acids for protein synthesis for skin and wool growth. This variable may add to explain inconsistencies observed in IMF deposition within and between studies involving oils as supplementary feed sources in sheep. 

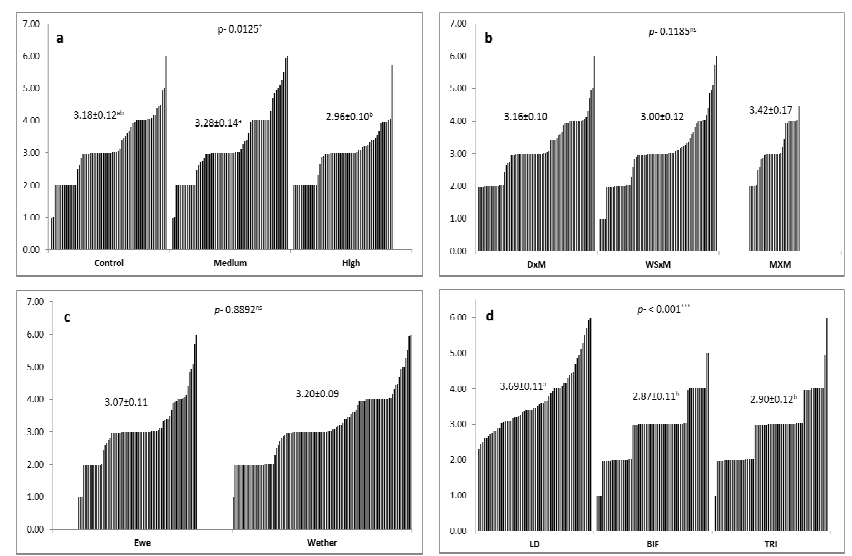

Figure 1. Variations in IMF percentages within and between level of DCCO supplementation (a), sire breed (b), sex (c) and muscle type (d) in 1 st cross prime lambs. Values above each muscle type represent the overall mean \pm standard error of the muscle type. Means bearing different superscripts significantly differ $(p<0.05)$. Level of significance: ${ }^{n s}$ not significant $(p>0.05),{ }^{*}$ significant $(p<0.05),{ }^{* *}$ highly significant $(p<0.01)$, ${ }^{* * *}$ very highly significant $(p<0.001)$.

\subsection{Sire Breeds Effects}

At first glance, it seemed IMF was higher in purebred Merinos (average of $3.42 \pm 0.17 \%$ and range of $2.00-5.94 \%$ ) compared to first-cross progeny sired by Dorset (average of $3.16 \pm 0.10 \%$ and range of $1.98-6.00 \%$ ) and White Suffolk (average of $3.00 \pm 0.12 \%$ and range of $0.99-6.00 \%$ ) as depicted in Figure 1b. However, these differences in IMF content between sire breeds were not significant $(p>0.1185)$ (Figure 1b). This result challenges our tested hypothesis and previous observations $[32,33,34]$ that IMF deposition is significantly affected by sire genetics. However, our results are comparable to those of [35] who also identified a lack of significant sire breed effects in IMF deposition between Aberdeen Angus and Limousin crossbreds. It has also been deduced that the lack of significant differentiation was more likely related to the limited number of animals used within each experimental group and/or the variations observed between individual animals within each breed [35]. Outcomes indicating that genetic variation within breeds are as extensive as variations between breeds within cattle and sheep, respectively, have been reported [36, 37]. This may account for the lack of significant differences observed between sire breeds in the present study. However, the lack of significant difference between sire breeds may have also been due to a dilution effect by the maternal genetics because all $F_{1}$ progeny were from Merino ewes. It may well be that significant variations between progeny from different sire breeds may have been evident if we had used $2^{\text {nd }}$-cross animals, or if animals were allowed to age longer during the trial before slaughtering.

While we observed insignificant sire breed $\mathrm{x}$ muscle type $(p>0.4231)$ and sire breed $x$ sex $(p>0.8058)$ interactions in Table 2, a significant sire breed $\mathrm{x}$ DCCO level of supplementation interaction $(\mathrm{p}<0.0016)$ was evident as portrayed in Figure 2. The greatest genetic variability within and between sire breeds under varying supplementation levels was observed in the Merino genotype compared to the other sire breeds studied, particularly under Medium levels of supplementation. This response by the purebred Merino, indicates that this may be where the significant differences between the genotype and DCCO supplementation interactions are coming from. Similarly, this may also be where the significant differences between Medium and High DCCO supplementation for fixed effects are coming from. One possible explanation for the Merino response to Medium supplementation may be individual animal responses, particularly given the limited number of Merinos supplemented at Medium levels. As such, this result may not truly reflect the effect of Medium DCCO supplementation on the Merino genotype.

\subsection{Sex Effects on Intramuscular Fat Deposition}

Male hormones such as testosterone, aid in rams producing heavier, leaner carcasses with significantly lower IMF than ewes of the same age [38]. However, it is recognised that castration removes the anabolic effects of male hormones with wethers producing a carcass composition that is analogous to that of wethers [39].

The effect of sex on IMF in this study was insignificant $(\mathrm{p}>0.8892)$ as shown on Figure $1 \mathrm{c}$ as the average IMF content in wethers $(3.20 \pm 0.09 \%)$ was similar to that of ewes $(3.07 \pm 0.11 \%)$ with both sexes recording identical minimum and maximum ranges between 0.99 and $6.00 \%$. Our results are supported by Okeudo and Moss (2007) [40] who also found that IMF contents in ewes and wethers were not significantly different when slaughtered from 180 to 390 days of age. However, McPhee et al., (2008) [15] found significant differences in IMF content between ewes and wethers in the LL muscle which increased with animal age, with a slaughter age of up to 22 months. This suggests that the lack of significant differences in our study may have been due to animal age at slaughter where potential growth and age at maturity effects between ewes and wethers had not become evident.

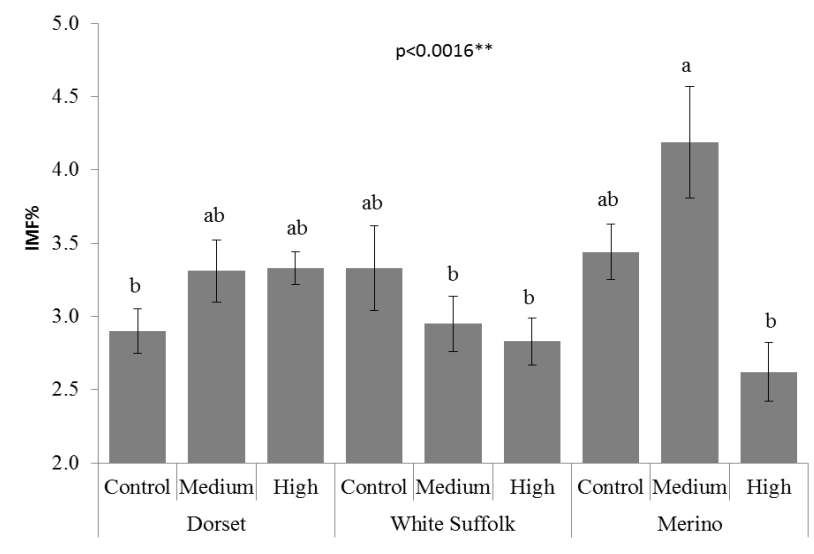

Figure 2. Interaction between sire breed and level of DCCO supplementation on IMF content (\%). Means bearing different superscripts are significantly different $(p<0.05)$. Level of significance: $* *$ highly significant $(p<0.01)$. 


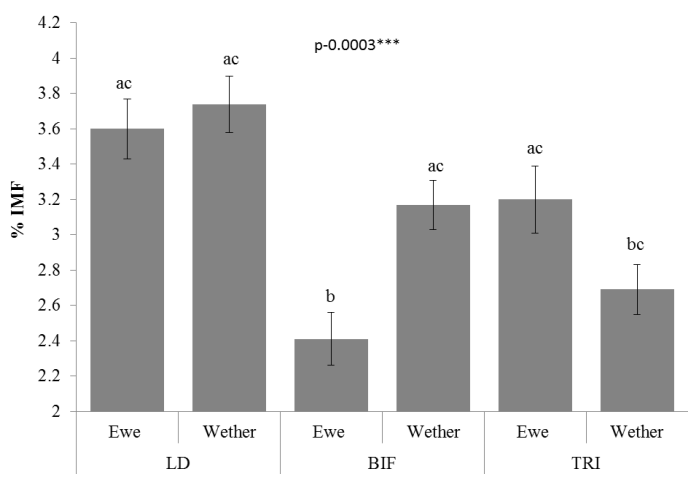

Figure 3. Interaction between sex and muscle type on IMF content (\%). Different superscripts imply significant differences within and between variables $(p<0.05)$. Level of significance: ${ }^{* * *}$ very highly significant.

A significant interaction between sex and muscle type $(\mathrm{p}<0.0003)$ was evident in our results as shown in Figure 3. Ewes had significantly lower $(2.41 \pm 0.15 \%)$ IMF than wethers $(3.17 \pm 0.14 \%)$ in the BIF, but higher $(3.20 \pm 0.19 \%)$ IMF than wethers $(2.69 \pm 0.14 \%)$ in the TRI. Our results are comparable to those of [41] who reported that when lambs were reared indoors, sex did not significantly affect the amount of IMF in the Longissimus and supraspinatus muscles, but significant differences were observed in the semi-membranosus muscles with IMF in females being higher than in males. Significant differences between muscle types in ewes and wethers have also been identified [42]. However, while the sex differences in the Longissimus dorsi was negligible, they reported that IMF content in the leg was higher in ewes than rams, and IMF in the shoulder muscle was lower in ewes compared to rams.

\subsection{Muscle Types}

Most recent studies assessing IMF levels in meat have focussed primarily on the Longissimus muscle mainly because it is a valuable component of high-value meat cuts. However, it is not the only muscle type eaten by consumers. Therefore, the intention of this study was to examine IMF deposition levels in various muscle types in lamb meat cuts that are often eaten by consumers. Results in Figure 1d showed significant differences in IMF content between muscle types $(\mathrm{p}<0.0001)$, with LD significantly higher $(2.69 \pm 0.11 \%)$ than both the TRI $(2.69 \pm 0.11 \%)$ and BIF $(2.87 \pm 0.11 \%)$. This was expected given previously published studies reporting that IMF increases from the posterior to the anterior portion of the carcass [43] and that the functional role of each muscle in animal movement produced higher IMF increases in the loin compared to shoulder and leg muscles [44]. Variation in IMF within the Longissimus muscle in beef has also been reported [45]. This lends credence to our findings in all muscle types studied (Figure 1d). Additionally, our results showing that the Longissimus muscle in sheep has relatively less variability in IMF when compared to other muscle types is supported by [43] who also demonstrated that IMF distribution in beef is considerably less variable in the Longissimus compared to other muscle types.

\subsection{Potential Effects on Meat Eating Quality}

The mean IMF values observed in this study suggest that the majority of all criteria assessed fell within the accepted ranges of the ideal meat eating quality outlined by [9].

The minimum and maximum IMF ranges observed in this study (Figures $1 \mathrm{a}, \mathrm{b}, \mathrm{c}$, and d) also demonstrate that variability exists within and between animals supplemented with degummed crude canola oil, as well as between muscles, genotypes and sexes. This indicates that IMF levels are highly variable not only between, but also within, the variables studied. Similarly, the variations between the minimum and maximum IMF levels observed in this study would likely influence individual consumer perceptions of the eating quality of the end product, and therefore their subsequent acceptance of what they perceive as a quality product. However, such identified differences by consumers would not only depend upon the anatomical site of sampling, but also on the preferences of the individual consumer.

Table 2. Interactions between muscle type, level of DCCO supplementation, sex and sire breed on IMF content.

\begin{tabular}{|c|c|c|}
\hline Interactions & & \%IMF \\
\hline muscle type & supplementation level & \\
\hline \multirow[t]{3}{*}{ LL } & Control & $3.72 \pm 0.14$ \\
\hline & Medium & $3.94 \pm 0.25$ \\
\hline & High & $3.34 \pm 0.16$ \\
\hline \multirow[t]{3}{*}{$\mathrm{BIF}$} & Control & $2.67 \pm 0.22$ \\
\hline & Medium & $3.14 \pm 0.20$ \\
\hline & High & $2.77 \pm 0.13$ \\
\hline \multirow[t]{3}{*}{ TRI } & Control & $3.14 \pm 0.20$ \\
\hline & Medium & $2.76 \pm 0.20$ \\
\hline & High & $2.78 \pm 0.19$ \\
\hline p-value & $0.0943^{\mathrm{ns}}$ & \\
\hline Sex & supplementation level & \\
\hline \multirow[t]{3}{*}{ Ewe } & Control & $3.02 \pm 0.21$ \\
\hline & Medium & $3.07 \pm 0.17$ \\
\hline & High & $3.15 \pm 0.22$ \\
\hline \multirow[t]{3}{*}{ Wether } & Control & $3.29 \pm 0.14$ \\
\hline & Medium & $3.44 \pm 0.21$ \\
\hline & High & $2.87 \pm 0.10$ \\
\hline p-value & $0.8779^{\mathrm{ns}}$ & \\
\hline Muscle type & Sire breed & \\
\hline \multirow[t]{3}{*}{ LL } & Dorset & $3.61 \pm 0.15$ \\
\hline & White Suffolk & $3.64 \pm 0.17$ \\
\hline & Merino & $3.93 \pm 0.35$ \\
\hline \multirow[t]{3}{*}{$\mathrm{BIF}$} & Dorset & $3.00 \pm 0.16$ \\
\hline & White Suffolk & $2.54 \pm 0.18$ \\
\hline & Merino & $3.25 \pm 0.25$ \\
\hline \multirow[t]{3}{*}{ TRI } & Dorset & $2.87 \pm 0.18$ \\
\hline & White Suffolk & $2.83 \pm 0.20$ \\
\hline & Merino & $3.08 \pm 0.23$ \\
\hline $\mathrm{p}$-value & $0.4231^{\mathrm{ns}}$ & \\
\hline Sire breed & Sex & \\
\hline \multirow[t]{2}{*}{ Dorset } & Ewe & $3.13 \pm 0.12$ \\
\hline & Wether & $3.19 \pm 0.17$ \\
\hline \multirow[t]{2}{*}{ White Suffolk } & Ewe & $3.01 \pm 0.19$ \\
\hline & Wether & $2.99 \pm 0.14$ \\
\hline Merino & Wether & $3.42 \pm 0.17$ \\
\hline p-value & $0.8058^{\mathrm{ns}}$ & \\
\hline
\end{tabular}

Levels of significance: ${ }^{\text {ns }}$ not significant . 


\section{Conclusion}

Supplementation of prime lambs with DCCO can be used as a management tool to vary the level of IMF content to suit different market specifications dictated by meat consumers. Whereas in themselves, the sex and sire breeds of lambs used in this study were not the primary drivers of IMF deposition, our results demonstrate that sheep farmers can modify their nutritional management and breed combinations by effectively utilizing appropriate sire breed and supplementation levels to manipulate the IMF content of various muscle types in ewe and wether prime lambs. Other performance indicators such as lamb body conformation, average daily gain, early attainment of slaughter weight, price competitiveness between supplementary feed sources and market-driven demands will be key considerations to factor in the desirable IMF equation.

\section{Acknowledgements}

We acknowledge with gratitude, the financial contribution of the Australian Wool Education Trust through honours scholarships for the wool component of the research. The first author is a recipient of the Commonwealth of Australia's Higher Degree by Research Student Postgraduate Award Scholarship through the University of Tasmania.

\section{References}

[1] Baghurst, K., Dietary fats, marbling and human health, 2004. Australian Journal of Experimental Agriculture 44, 635-644.

[2] McAfee, A. J., McSorley, E. M., Cuskelly, G. J., Moss, B. W., Wallace, J. M. W., Bonham, M. P., Fearon, A. M., 2010. Red meat consumption: An overview of the risks and benefits. Meat Science 84, 1-13.

[3] Wood, J. D., Enser, M., Fisher, A. V., Nute, G. R., Whittington, F. M., Richardson, R. I., 2005. Effects of diets on fatty acids and meat quality. Options Mediterraneennes. Serie A, Seminaires Mediterraneens 5, 133-141.

[4] Webb, E. C., O'Neill, H. A., 2008. The animal fat paradox and meat quality. Meat Science 80, 28-36.

[5] Ngapo, T. M., Martin, J. F., Dransfield, E., 2007. International preferences for pork appearance: I. Consumer choices. Food Quality and Preference 18, 26-36.

[6] Fernandez, X., Monin, G., Talmant, A., Mourot, J., Lebret, B., 1999. Influence of intramuscular fat content on the quality of pig meat - 2. Consumer acceptability of $M$. longissimus lumborum. Meat Science 53, 67-72.

[7] Thompson, J. M., 2004. The effects of marbling on flavour and juiciness scores of cooked beef, after adjusting to a constant tenderness. Australian Journal of Experimental Agriculture 44, 645-652.

[8] Wood, J. D., Enser, M., Fisher, A. V., Nute, G. R., Sheard, P. R., Richardson, R. I., Hughes, S. I., Whittington, F. M., 2008. Fat deposition, fatty acid composition and meat quality: A review. Meat Science 78, 343-358.

[9] Savell, J., Cross, H., 1988. The role of fat in the palatability of beef, pork, and lamb. Designing Foods: Animal Product Options in the Marketplace. National Academy Press, Washington, DC.

[10] Hopkins, D. L., Hegarty, R. S., Walker, P. J., Pethick, D. W., 2006. Relationship between animal age, intramuscular fat, cooking loss, $\mathrm{pH}$, shear force and eating quality of aged meat from sheep. Australian Journal of Experimental Agriculture 46, 879-884.

[11] Hart, R., 2001. The Physiology of marbling: What is it, and why does it develop. In: Marbling Symposium, October, Coffs Harbour, NSW, Australia.

[12] Chriki, S., Picard, B., Faulconnier, Y., Micol, D., Brun, J.-P., Reichstadt, M., Jurie, C., Durand, D., Renand, G., Journaux, L., Hocquette, J.-F., 2013. A data warehouse of muscle characteristics and beef quality in France and a demonstration of potential applications. Italian Journal of Animal Science 12, 247-256.

[13] Johnson, E. R., 1987. Marbling fat in beef. Meat Science 20, 267-279.

[14] Johnson, E. R., Pryor, W. J., Butterfi, RM., 1973. Studies of fat distribution in bovine carcass.2. Relationship of intramuscular fat to quantitative-analysis of skeletal musculaturel. Australian Journal of Agricultural Research 24, 287-296.

[15] McPhee, M. J., Hopkins, D. L., Pethick, D. W., 2008. Intramuscular fat levels in sheep muscle during growth. Australian Journal of Experimental Agriculture 48, 904-909.

[16] Shackelford, S. D., Leymaster, K. A., Wheeler, T. L., Koohmaraie, M., 2012. Effects of breed of sire on carcass composition and sensory traits of lamb. Journal of Animal Science 90, 4131-4139.

[17] Craigie, C. R., Lambe, N. R., RichardsonI, R. I., Haresign, W., Maltin, C. A., RehfeldtE, C., Roehe, R., Morris, S. T., Bunger, L., 2012. The effect of sex on some carcass and meat quality traits in Texel ewe and ram lambs. Animal Production Science 52, 601-607.

[18] Cho, S. H., Park, B. Y., Kim, J. H., Hwang, I. H., Kim, J. H., Lee, J. M., 2005. Fatty acid profiles and sensory properties of Longissimus dorsi, Triceps brachii, and Semimembranosus muscles from Korean Hanwoo and Australian Angus beef. Asian-Australasian Journal of Animal Science 18, 1786-1793.

[19] Fisher, A. V., Enser, M., Richardson, R. I., Wood, J. D., Nute, G. R., Kurt, E., Sinclair, L. A., Wilkinson, R. G., 2000. Fatty acid composition and eating quality of lamb types derived from four diverse breed x production systems. Meat Science $55,141-147$.

[20] Pethick, D. W., Davidson, R., Hopkins, D. L., Jacob, R. H., D'Souza, D. N., Thompson, J. M., Walker, P. J., 2005. The effect of dietary treatment on meat quality and on consumer perception of sheep meat eating quality. Australian Journal of Experimental Agriculture 45, 517-524.

[21] Smith, S. B., Crouse, J. D., 1984. Relative contributions of acetate and glucose to lipogenesis in bovine intramuscular and subcutaneous adipose-tissue. Journal of Nutrtion $114: 792-800$ 
[22] Pethick, D. W., Harper, G. S., Oddy, V. H., 2004. Growth, development and nutritional manipulation of marbling in cattle: a review. Australian Journal of Experimental Agriculture 44, 705-715.

[23] Hess, B. W., Moss, G. E., Rule, D. C., 2008. A decade of developments in the area of fat supplementation research with beef cattle and sheep. Journal of Animal Science 86, E188-204.

[24] Folch, J., Lees, M., Stanley, G. H. S., 1957. A simple method for the isolation and purification of total lipides from animal tissues. Journal of Biological Chemistry 226, 497-509.

[25] SAS 2009. Statistical Analysis System. SAS Institute, Cary, NC, USA, Version 9.2.

[26] Bessa, R. J. B., Portugal, P. V., Mendes, I. A., Santos-Silva, J., 2005. Effect of lipid supplementation on growth performance, carcass and meat quality and fatty acid composition of intramuscular lipids of lambs fed dehydrated lucerne or concentrate. Livestock Production Science 96, 185-194.

[27] Bolte, M. R., Hess, B. W., Means, W. J., Moss, G. E., Rule, D. C., 2002. Feeding lambs high-oleate or high-linoleate safflower seeds differentially influences carcass fatty acid composition. Journal of Animal Science 80, 609-616.

[28] Radunz, A. E., Wickersham, L. A., Loerch, S. C., Fluharty, F. L., Reynolds, C. K., Zerby, H. N., 2009. Effects of dietary polyunsaturated fatty acid supplementation on fatty acid composition in muscle and subcutaneous adipose tissue of lambs. Journal of Animal Science 87, 4082-4091.

[29] Marinova, P., Popova, T., Banskalieva, V., Raicheva, E., Ignatova, M., Vasileva, V., 2007. Effect of fish oil supplemented diet on the performance, carcass composition and quality in lambs. Bulgarian Journal of Agricultural Science 13, 729-737.

[30] Popova, T., Ignatova, M., Marinova, P., Abadjieva, D., 2011. Effect of coconut oil supplementation on the carcass composition and muscle physicochemical characteristics in lambs. Biotechnology in Animal Husbandry 27, 1139-1145.

[31] Bermingham, E. N., Liu, S. M., Briegel, J. R., Greeff, J. C., Adams, N. R., 2004. Glucose production in Merino ewes selected for high fleece weight. Animal Production in Australia. Proceedings of the Australian Society of Animal Production 25, 218-218.

[32] Hopkins, D. L., Stanley, D. F., Martin, L. C., Toohey, E. S., Gilmour, A. R., 2007. Genotype and age effects on sheep meat production 3. Meat quality. Australian Journal of Experimental Agriculture 47, 1155-1164.

[33] Liu, Y., Ma, T., Du, W., Hao, H., Wang, D., Zhao, X., Li, H., Jiang, Q., Zhu, H., 2012. Genes Expression Related to Intramuscular Fat Deposition in Muscles of Small Tail Han
Sheep. Journal of Animal and Veterinary Advances 11, 3969-3977.

[34] Shackelford, S. D., Leymaster, K. A., Wheeler, T. L., Koohmaraie, M., 2012. Effects of breed of sire on carcass composition and sensory traits of lamb. Journal of Animal Science 90, 4131-4139.

[35] Ward, R. E., Woodward, B., Otter, N., Doran, O., 2010. Relationship between the expression of key lipogenic enzymes, fatty acid composition, and intramuscular fat content of Limousin and Aberdeen Angus cattle. Livestock Science 127, 22-29.

[36] Baud, S., Goddard, M., Hygate, L., 1994. Targeting the Japanese Beef Market. Final Report, Meat Research Corporation Project M.112. 26

[37] Fogarty, N. M., Hopkins, D. L., Ven, R. van de., 2000. Lamb production from diverse genotypes 1 . Lamb growth and survival and ewe performance. Journal Animal Science 2000, 135-145.

[38] Craigie, C. R., Lambe, N. R., RichardsonI, R. I., Haresign, W., Maltin, C. A., RehfeldtE, C., Roehe, R., Morris, S. T., Bunger, L., 2012. The effect of sex on some carcass and meat quality traits in Texel ewe and ram lambs. Animal Production Science 52, 601-607.

[39] Warriss, P. D., 2010. Meat Science: An introductory text. $2^{\text {nd }}$ Edition. Commonwealth Agricultural Bureaux International, Oxfordshire, UK.

[40] Okeudo, N. J., Moss, B. W., 2007. Intramuscular lipid and fatty acid profile of sheep comprising four sex-types and seven slaughter weights produced following commercial procedure. Meat Science 76, 195-200.

[41] Vasileva, V., Marinova, P., Popova, T., 2009. Influence of the rearing system and sex on the adipocyte size and distribution in different fat depots in lambs. Bulgarian Journal of Agricultural Science 15, 257-262.

[42] Abouehif, M., Kraidees, M., Shatat, R., 1993. Partitioning of lipid in the body of fat-tailed lambs as influenced by docking and sex. Asian-Australasian Journal of Animal Science 6, 79-86.

[43] Cross, H. R., Abraham, H. C., Knapp, E. M., 1975. Variations in the amount, distribution and texture of intramuscular fat within muscles of the beef carcass. Journal of Animal Science 41, 1618-1626.

[44] Pryor, W. J., Warren, G. H., 1973. Chemical fat in musculature of sheep carcass. Journal of Agricultural Science 80, 219-224.

[45] Blumer, T. N., Wise, M. B., Pierce, E. A., Smart, W. W. G., Craig, H. B., 1962. Nature and variability of marbling deposits in longissimus-dorsi muscle of beef carcasses. Journal of Animal Science 21, 935-938. 